\title{
PELATIHAN DAN SOSIALISASI SISTEM INFORMASI KEUANGAN PADA SEKOLAH ISLAM TERPADU PEKANBARU
}

\author{
Muhammad Sadar ${ }^{1}$, Wenni Syafitri ${ }^{2}$, Eddisyahputra Pane ${ }^{3}$ \\ ${ }^{1,2}$ Program Studi Teknik Informatika, ${ }^{3}$ Program Studi Sistem Informasi, Fakultas Ilmu Komputer \\ Universitas Lancang Kuning \\ *E-mail: sadar@dr.com
}

\begin{abstract}
Abstract SMP IT Madani apply concept of islamic in its education practice. Madani is a school formed by amil zakat self-supporting institution (Swadaya ummah Riau). Its using the concept of free school. The average students who attend junior high school IT is students who come from poor families. Madani has received School Operational Assistance (BOS) for few years. The obligations of schools of receiving BOS programs should reported realization to government. Currently schools are having difficulties to make reporting realization of BOS program to government and foundation. Differences in reporting formats to foundations and governments, make school getting serious problems. When interviewed, Madani is very eager and want to resolved immediately. Based on problems, it can be concluded solution about reporting information system synchronized to government and foundation. Unilak increasingly fragrant in this society, especially SMP IT Madani. Method of this actvitity is direct observation of partners location (first phase). Then, we will held second phase, socialization about benefits of synchronizing of Governament's BOS reporting and foundation. Third stage, authors design and implementation of BOS reporting system. Finally, training phase: SMP IT send two participant, to attend training of using reporting system.
\end{abstract}

Keywords-BOS, Financial Report, Information System

\begin{abstract}
Abstrak
Abstrak SMP IT Madani sebagai salah satu sekolah yang menerapkan konsep islami di dalam praktek pendidikan. Madani merupakan sekolah yang dibentuk oleh lembaga amil zakat swadaya ummah Riau, menggunakan konsep sekolah bebas biaya. Rata-rata siswa Madani adalah siswa berasal dari keluarga tidak mampu. Madani telah mendapat Bantuan Operasional Sekolah (BOS) beberapa tahun ini. Kewajiban dari sekolah yang mendapatkan program BOS yaitu melaporkan realisasi pemanfaatan program kepada pemerintah. Saat ini sekolah mengalami kesulitan membuat pelaporan realisasi program BOS. Perbedaan format pelaporan yayasan dan pemerintah membuat pihak sekolah mengalami permasalahan serius. Ketika dilakukan wawancara, pihak sekolah ingin permasalahan diselesaikan segera. Berdasarkan Permasalahan mitra tersebut, diambillah solusi yaitu dibangunnya sistem informasi pelaporan yang sinkron antara pemerintah dan yayasan. Sehingga Madani tidak mengalami kendala pelaporan program BOS. Alhasil, nama Unilak semakin harum dimata masyarakat, khususnya SMP IT Madani. Metode pelaksanaan yang digunakan adalah observasi langsung ke lokasi mitra (tahap pertama). Tahap kedua yaitu sosialisasi manfaat sinkronisasi pelaporan BOS terhadap pemerintah dan yayasan. Selanjutnya tahap ketiga, penulis melakukan perancangan dan implementasi sistem pelaporan BOS berdasarkan informasi yang diperoleh. Terakhir, tahap pelatihan yaitu SMP IT mengirimkan dua orang perwakilan, mengikuti pelatihan penggunaan sistem pelaporan.
\end{abstract}

Kata kunci-BOS, Laporan Keuangan, Sistem Informasi

\section{PENDAHULUAN}

SMP IT Madani sebagai salah satu sekolah yang menerapkan konsep islami di dalam praktek pendidikannya. SMP IT Madani merupakan sekolah yang dibentuk oleh lembaga amil zakat swadaya ummah Riau dengan menggunakan konsep sekolah bebas biaya. SMP IT berdiri 
pada tahun 2011 dengan jumlah siswa sebanyak 20 orang. Seiring berjalannya waktu, saat ini jumlah siswa SMP IT Madani berjumlah sebanyak 75 siswa. Rata-rata siswa yang bersekolah di SMP IT ini adalah siswa yang berasal dari keluarga tidak mampu.

SMP IT Madani telah mendapat Bantuan Operasional Sekolah (BOS) beberapa tahun belakang ini. Program BOS menggunakan pendekatan yang berbeda dari Bantuan Khusus Murid (BKM) yaitu dana BOS tidak diberikan kepada siswa miskin tetapi diberikan kepada sekolah serta dikelola oleh sekolah. Mekanisme perhitungan dana BOS berdasarkan jumlah murid di masingmasing sekolah. Sehingga tujuan BOS ini dapat tercapai yaitu membebaskan biaya pendidikan bagi siswa miskin ataupun tidak mampu serta dapat meringankan bagi siswa yang lain agar mereka dapat memperoleh layanan pendidikan dasar 9 tahun.

Kewajiban dari sekolah yang mendapatkan program BOS harus melaporkan realisasi pemanfaatan program tersebut kepada pemerintah. Saat ini sekolah mengalami kesulitan untuk membuat pelaporan realisasi program BOS kepada pemerintah dan yayasan. Perbedaan format pelaporan terhadap yayasan dan pemerintah membuat pihak sekolah mengalami permasalahan yang serius. Jika tidak sinkron antar pelaporan antara pemerintah dan yayasan akan menimbulkan banyak pertanyaan dan masalah lainnya. Ketika dilakukan wawancara, pihak sekolah sangat ingin sekali permasalahan ini diselesaikan segera. Berikut bentuk aplikasi laporan Bos yang harus diinput oleh staf administrasi SMP IT Madani :

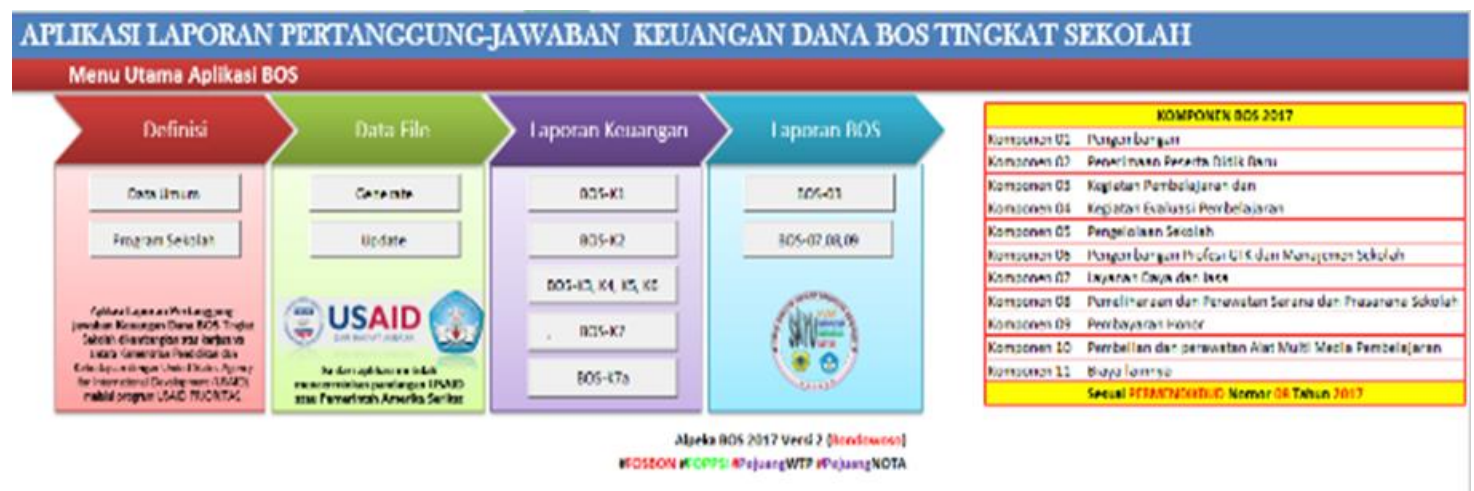

Gambar 1 Bentuk Aplikasi Laporan BOS

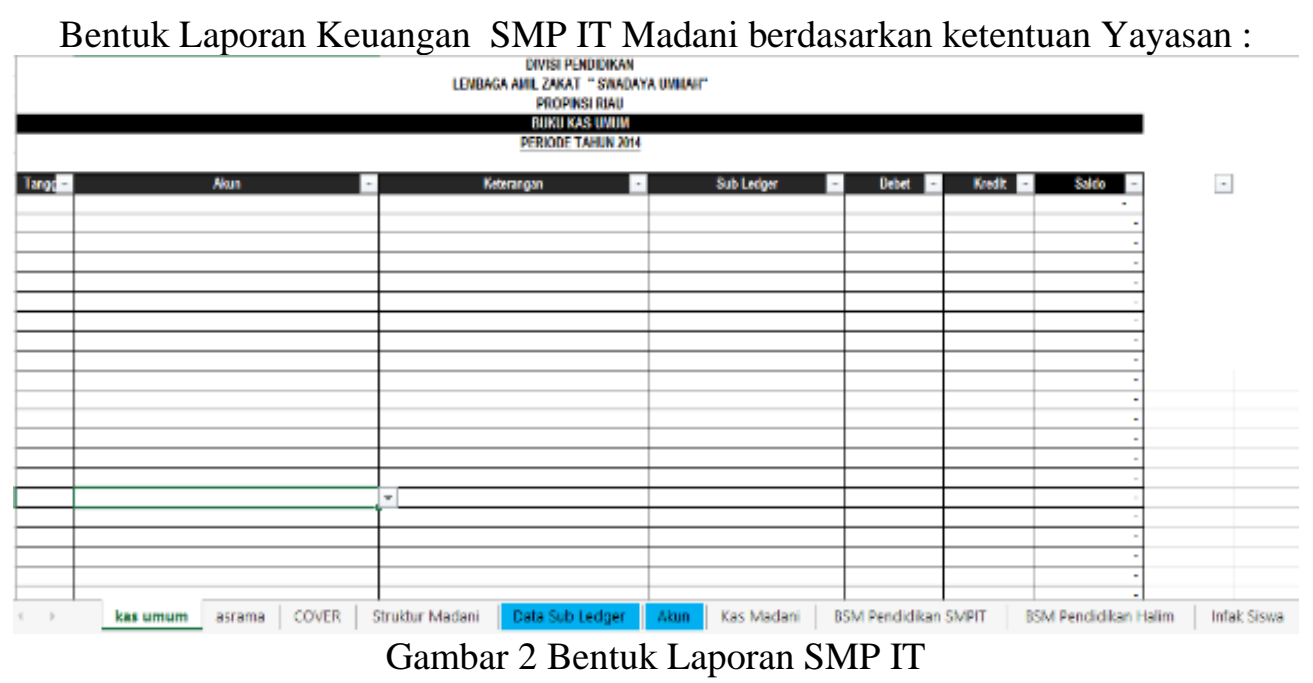

\section{TARGET DAN LUARAN}

Solusi dan target keluaran yang diharapkan adalah agar SMP IT Madani menerapkan sistem informasi pelaporan BOS.

Solusi yang ditawarkan sebagai bentuk pengabdian masyarakat, sebagai berikut: 
1. Sebuah sistem informasi pelaporan program BOS yang singkron antara pelaporan pemerintah dan yayasan.

2. Melakukan instalasi dan pelatihan penggunaan sistem informasi pelaporan program BOS pada SMP IT Madani, sehingga pemanfaatan teknologi informasi lebih terasa bagi yang membutuhkan.

Permasalahan ini dapat diselesaikan dengan sebuah sistem pelaporan berdasarkan dari beberapa rekomendasi penelitian seperti[1], [2], [11]-[18], [3]-[10].

Proses pencapaian keluaran yang diharapkan dapat diuraikan sebagai berikut:

1. Keadaan awal sekolah terkendala sinkronisasi antara laporan keuangan versi BOS kepada pemerintah dan yayasan, sehingga perlu diberikan pengarahan melalui sosialisasi pemanfaatan pelaporan yang saling sinkronisasi.

2. Keadaan pertengahan, SMP IT Madani mulai mengetahui manfaat terhadap pelaporan keuangan yang sinkron antara laporan keuangan BOS dan Yayasan.

3. Keadaan akhir, diharapkan peserta dapat menggunakan sistem informasi keuangan yang saling sinkron antara pemerintah (BOS) dan yayasan.

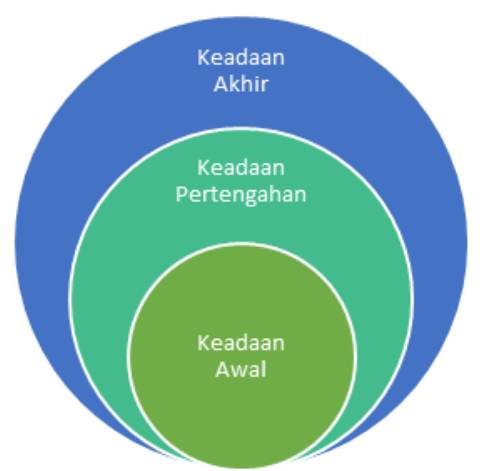

Gambar 3 Proses Pencapaian Keluaran Pengabdian Masyarakat

\section{METODE DAN PELAKSANAAN}

Metode pendekatan yang digunakan adalah observasi langsung ke lokasi mitra untuk melakukan tahap pertama, tahapan ini meliputi pengumpulan data dan pengolahan data. Ketika tahap ini berlangsung, akan diperoleh gambaran lingkungan Teknologi Informasi, dan kebutuhan mitra terhadap mekanisme pelaporan keuangan program BOS dan Yayasan. Setelah tahap pertama terlaksana, maka akan dilaksanakan tahap kedua yaitu sosialisasi, tahapan ini melakukan sosialisasi tentang manfaat melakukan sinkronisasi pelaporan BOS terhadap pemerintah dan yayasan. Terakhir, tahap pelatihan yaitu Setiap sekolah mitra mengirimkan perwakilannya dua orang, untuk mengikuti pelatihan penggunaan sistem pelaporan yang dapat melakukan sinkronisasi terhadap pelaporan BOS dan yayasan.

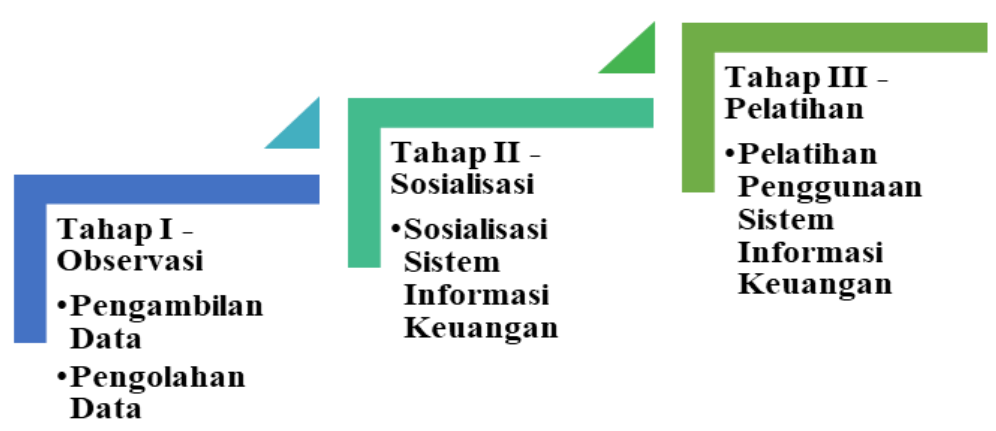

Gambar 4 Tahapan Pelaksanaan 
Keluaran yang diharapkan adalah sebuah sistem informasi yang membantu proses pelaporan program BOS oleh SMP IT Madani telah dapat sinkronisasi terhadap pemerintah dan yayasan.

\section{KELAYAKAN TIM PELAKSANA}

Tim pelaksana pengabdian Program pada mitra yaitu SMP IT Madani dengan keahliannya masing-masing adalah sebagai berikut :

Ketua : $\quad$ Muhammad Sadar, M.Kom

Keahlian : Ketua tim pengabdian memiliki keahlian dalam bidang teknologi informasi serta yang akan melakukan analisa terhadap permasalahan yang dihadapi mitra.

Berikut penjelasan tambahan mengenai pengalaman dan kompetensi yang dimiliki ketua tim :

Tabel 1 Kelayakan Ketua Tim

\begin{tabular}{|c|c|c|}
\hline Pengalaman Tim Pengabdian & $\begin{array}{l}\text { Matakuliah yang } \\
\text { pernah diampu }\end{array}$ & Kompetensi yang dimiliki \\
\hline Tahun 2016 : & $\begin{array}{l}\text { 1. Kewirausahaan } \\
\text { 2. Dasar Akuntansi }\end{array}$ & $\begin{array}{l}\text { Personal komunikasi } \\
\text { yang baik }\end{array}$ \\
\hline $\begin{array}{l}\text { Training Instalasi Dan Pengelolaan } \\
\text { Maintenance Jaringan Komputer Pada } \\
\text { Sekolah Islam Terpadu Pekanbaru }\end{array}$ & $\begin{array}{l}\text { 3. Sistem Informasi } \\
\text { Akuntansi } \\
\text { 4. Akuntansi Lanjutan }\end{array}$ & 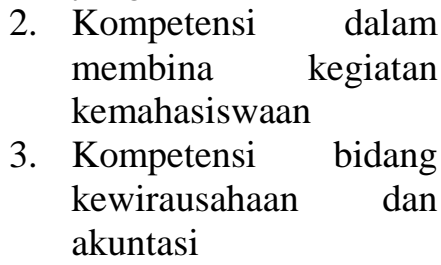 \\
\hline
\end{tabular}

Berdasarkan tabel diatas, Ketua tim pengabdian memiliki kemampuan yang mumpuni dan layak untuk melaksanakan pengabdian masyarakat ini.

$\begin{array}{lll}\begin{array}{l}\text { Anggota 1 } \\ \text { Keahlian }\end{array} & : & \begin{array}{l}\text { Wenni Syafitri, S.T., M.T.I } \\ \text { Tim pengabdian (anggota 1) memiliki keahlian dalam bidang } \\ \text { implementasi sistem informasi keuangan. }\end{array} \\ \begin{array}{l}\text { Anggota 2 } \\ \text { Keahlian }\end{array} & : & \begin{array}{l}\text { Eddis Syahputra Pane, M.Kom } \\ \text { Tim pengabdian (anggota 2) memiliki keahlian dalam bidang } \\ \text { implementasi sistem informasi Keuangan. }\end{array}\end{array}$

\section{HASIL DAN LUARAN YANG DICAPAI}

Pengabdian kepada masyarakat dilakukan melalui 2 tahapan yaitu sosisalisasi kegiatan ibm dan pelaksanaan kegiatan tersebut. Tahapan sosialisasi dilakukan pada mitra. Berikut detil kegiatan yang telah dilakukan:

\section{Tahapan Pertama : Sosialisasi}

SMP IT Madani masih menggunakan 2 buah format laporan keuangan yang digunakan yaitu format Yayasan dan format laporan dari program pemerintah "BOS". Ketika kami melakukan sosialiasi untuk menemukan solusi bagi sekolah tersebut, pihak sekolah sangat antusias sekali terhadap solusi yang ditawarkan yaitu system keuangan yang mampu mengakomodir 2 buah laporan sekaligus.

\section{Tahapan Kedua : Pelatihan}


Pelaksanaan pelatihan penggunaan sistem dilakukan secara bertahap pada SMP IT Madani yaitu pada hari sabtu tanggal 28 April 2018 10.30-12.00. peserta pelatihan ini ditujukan kepada operator dan pihak Yayasan.

Mekanisme kegiatan ini dilakukan dalam dua sesi yaitu sesi presentasi oleh pemateri dan sesi workshop. Materi disampaikan kurang lebih 1 jam kemudian dilanjutkan dengan workshop. Sesi workshop lebih banyak didominasi dengan kegiatan teknis, seperti tips dan trik agar cepat faham terhadap materi yang akan dipelajari.

\section{Pengukuran}

Tingkat keberhasilan kegiatan pengabdian ini dapat diukur dengan menggunakan kuisioner. Validitas kuisioner dapat dilakukan dengan menggunakan skala gutman. Kuisioner ini terdiri dari 7 buah pertanyaan untuk PRE-TEST dan POST-TEST dengan skor setiap jawaban dari pertanyaan adalah YA dan TIDAK. untuk dapat menghitung skala Guttman dibutuhkan error dari masing-masing jawaban dari pertanyaan[19]. Berikut hasil pengolahan nilai Kuisioner PRE-TEST dan POST-TEST. PRE-TEST ini adalah mekanisme untuk menguji, apakah butir kuisioner teruji keandalannya sehingga dapat digunakan nantinya. Sedangkan tahap POST-TEST adalah mekanisme untuk melihat apakah kesuksesan implementasi pengabdian masyarakat telah terpenuhi atau tidak.

Tabel 2 Instrumen Penilaian Post dan Pre Test

\begin{tabular}{cll}
\hline NO & \multicolumn{1}{c}{ PERTANYAAN } & \multicolumn{2}{c}{ JAWABAN } \\
\cline { 2 - 3 } $\mathbf{1}$ & $\begin{array}{l}\text { Apakah bapak/ibu mengetahui tentang proses akses aplikasi laporan } \\
\text { keuangan? }\end{array}$ \\
\hline $\mathbf{2}$ & Apakah bapak/ibu mengetahui tentang proses pengelolaan master data? \\
\hline $\mathbf{3}$ & $\begin{array}{l}\text { Apakah bapak/ibu mengetahui tentang proses pengelolaan periode } \\
\text { kegiatan? }\end{array}$ \\
\hline $\mathbf{4}$ & $\begin{array}{l}\text { Apakah bapak/ibu mengetahui tentang proses pengelolaan perencanaan } \\
\text { keuangan? }\end{array}$ \\
\hline $\mathbf{5}$ & $\begin{array}{l}\text { Apakah bapak/ibu mengetahui tentang proses pengelolaan realisasi } \\
\text { keuangan? }\end{array}$ \\
\hline $\mathbf{6}$ & $\begin{array}{l}\text { Apakah bapak/ibu mengetahui tentang cara memperoleh tampilan laporan } \\
\text { keuangan bos dan Yayasan? }\end{array}$ \\
\hline $\mathbf{7}$ & $\begin{array}{l}\text { Apakah bapak/ibu mengetahui tentang proses pengelolaan keuangan } \\
\text { Yayasan? }\end{array}$ \\
\hline
\end{tabular}

\section{Koefisien Reprodusibilitas (CR)}

Koefisien Reprodusibilitas menunjukkan derajat keandalan pengukuran dengan skala yang dipakai yang terlihat dari persentase respons murni yang dapat direproduksi dari skor skala yang dipakai untuk merangkumnya. Nilai CR yang dapat diterima menurut [19]-[23] adalah $\geq 0.90$.

Rumus:

$$
C R=1-\left(\frac{T E}{P E}\right)
$$

Keterangan:

TE $=$ Jumlah eror semua dari semua subjek

$\mathrm{PE}=$ Jumlah eror yang kemungkinan terjadi. (Didapatkan dari perkalian antara jumlan subjek (N) dan jumlah butir (k))

\section{Koefisien Skalabilitas (CS)}

skala yang mengukur apakah penyimpangan pada skala reprodusibilitas masih dalam batas yang dapat di tolerir. Nilai CS yang dapat diterima menurut adalah $\geq 0.60$. 


$$
C S=1-\left[\frac{T E}{T E x Z}\right]
$$

Keterangan:

$\mathrm{TE}=$ Jumlah eror semua dari semua subjek

$\mathrm{Z}=$ Jumlah Kesalahan yang diterapkan (c(PE-Tn)), dimana $\mathrm{c}$ adalah kemungkinan mendapatkan jawaban yang benar atau sama dengan $\mathrm{c}=0,5$

$\mathrm{Tn}=$ Jumlah Pilihan Jawaban

Tabel 3 Hasil Pre-Test

\begin{tabular}{llllllllll}
\hline RESPONDEN & VA1 & VA2 & VA3 & VA4 & VA5 & VA6 & VA7 & Jumlah & Error \\
\hline $\mathbf{1}$ & 1 & 1 & 2 & 2 & 1 & 2 & 2 & 11 & 0 \\
\hline $\mathbf{2}$ & 2 & 2 & 2 & 2 & 2 & 2 & 2 & 14 & 0 \\
\hline $\mathbf{3}$ & 1 & 2 & 2 & 2 & 2 & 2 & 2 & 13 & 0 \\
\hline Total & & & & & & & & 38 & 0 \\
\hline
\end{tabular}

Tabel 4 Sebaran nilai kuisioner

\begin{tabular}{lll}
\hline PESERTA & YA & TIDAK \\
\hline $\mathbf{1}$ & 3 & 4 \\
\hline $\mathbf{2}$ & 0 & 2 \\
\hline $\mathbf{3}$ & 1 & 6 \\
\hline
\end{tabular}

Berdasarkan Tabel 3 Diketahui jumlah Responden adalah 3 orang, jumlah butir pertanyaan berjumlah 7 buah (VA) dan Total Error (TE) adalah 0, maka: nilai PE adalah 7 x $3=21$. Sehigga jika dimasukkan ke dalam rumus koefisien Repodusibilitas maka nilai CR sebagai berikut:

$$
\begin{aligned}
& C R=1-\left(\frac{0}{21}\right) \\
& C R=1
\end{aligned}
$$

Sedangkan untuk nilai skalabilitas, diketahui nilai $\mathrm{Tn}=38$ sebagai berikut:

$$
\begin{aligned}
& C S=1-\left[\frac{0}{0 x(0.5 x(21-38))}\right] \\
& C S=1
\end{aligned}
$$

Tabel 5. Hasil Post Test

\begin{tabular}{cccccccccc}
\hline Responden & VA1 & VA2 & VA3 & VA4 & VA5 & VA6 & VA7 & Jumlah & Error \\
\hline $\mathbf{1}$ & 1 & 1 & 1 & 1 & 1 & 1 & 1 & 7 & 0 \\
\hline $\mathbf{2}$ & 1 & 1 & 2 & 2 & 1 & 2 & 2 & 11 & 0 \\
\hline $\mathbf{3}$ & 1 & 2 & 2 & 2 & 2 & 2 & 2 & 13 & 0
\end{tabular}


DINAMISIA - Jurnal Pengabdian Kepada Masyarakat Vol. 2, No. 2 Desember 2018, Hal. 211-219

Total $31 \quad 0$

Tabel 6. Sebaran nilai kusioner

\begin{tabular}{ccc}
\hline PESERTA & YA & TIDAK \\
\hline $\mathbf{1}$ & 7 & 0 \\
\hline $\mathbf{2}$ & 3 & 4 \\
\hline $\mathbf{3}$ & 1 & 6
\end{tabular}

Berdasarkan Tabel 5, dapat diuraikan yaitu Diketahui jumlah Responden adalah 3 orang, jumlah butir pertanyaan berjumlah 7 buah (VA) dan Total Error (TE) adalah 0, maka: nilai PE adalah 7 x $3=21$. Sehigga jika dimasukkan ke dalam rumus koefisien Repodusibilitas maka nilai CR sebagai berikut:

$$
\begin{aligned}
& C R=1-\left(\frac{0}{21}\right) \\
& C R=1
\end{aligned}
$$

Sedangkan untuk nilai skalabilitas, diketahui nilai $\mathrm{Tn}=31$ sebagai berikut:

$$
\begin{aligned}
& C S=1-\left[\frac{0}{0 x(0.5 x(21-31))}\right] \\
& C S=1
\end{aligned}
$$

\section{Evaluasi Hasil}

Pada hasil pengukuran PRE-TEST tingkat keandalan butir pertanyaan telah maksimal dengan skala error 1. Hal ini dapat ditarik kesimpulan bahwa kuisioner telah dapat disebarkan dan memiliki tingkat pemahaman yang mudah. Setelah kegiatan dilaksanakan, kami kembali melakukan sebaran kuisioner POST-TEST. Setelah dihitung diperoleh hasil yang sangat memuaskan yaitu 1 .

\section{KESIMPULAN}

Berdasarkan kegiatan pengabdian yang telah dilaksanakan yaitu melakukan proses sosialisasi dan training, kami telah berhasil melakukan program transfer knowledge kepada mitra. Hal ini telah dibuktikan dengan evaluasi menggunakan kuisioner dengan pengujian Skala Guttman, yang mana nilai Koefisien Reprodusibilitas (CR) dan Koefisien Skalabilitias (CS) sebelum pelaksanaan dan setelah kegiatan pengabdian masyarakat adalah 1 .

\section{SARAN}

Berdasarkan hasil pengabdian yang telah dilakukan, maka kami menyarankan setiap SMP IT Yang menggunakan program BOS, dapat menggunakan sistem yang telah kami bangun.

\section{UCAPAN TERIMA KASIH}


Penulis mengucapkan terima kasih kepada Universitas Lancang Kuning yang telah memberi dukungan financial terhadap penelitian ini.

\section{DAFTAR PUSTAKA}

[1] P. Mulyani and R. F. Suryawati, "Analisis peran dan fungsi sistem pengendalian intern pemerintah (spip/pp no.60 tahun 2008) dalam meminimalisasi tingkat salah saji pencatatan akuntansi keuangan pemerintah daerah," J. Organ. dan Manaj., vol. 7, no. 2, pp. 102-116, 2011.

[2] S. Yuliani, N. Nadirsyah, and U. Bakar, "INTERNAL AUDIT TERHADAP KUALITAS LAPORAN KEUANGAN PEMERINTAH DAERAH ( Studi pada Pemerintah Kota Banda Aceh ) Safrida Yuliani Nadirsyah Usman Bakar JURNAL TELAAH \& RISET AKUNTANSI," J. TELAAH Ris. Akunt., vol. 3, no. 2, pp. 206-220, 2010.

[3] S. P. Sari and B. Witono, "KETERANDALAN DAN KETEPATWAKTUAN PELAPORAN KEUANGAN DAERAH DITINJAU DARI SUMBER DAYA MANUSIA, PENGENDALIAN INTERNAL DAN PEMANFAATAN TEKNOLOGI INFORMASI," in Seminar Nasional dan Call for Paper (Sancall 2014): RESEARCH METHODS AND ORGANIZATIONAL STUDIES, 2014, no. Sancall, pp. 418-425.

[4] F. ARIESTA, "Pengaruh Kualitas Sumberdaya Manusia, Pemanfaatan Teknologi Informasi, Dan Pengendalian Intern Akuntansi Terhadap Nilai Informasi Pelaporan Keuangan Pemerintah Daerah ( Studi pada Satuan Kerja Perangkat Daerah di Kabupaten Pasaman Barat)," J. Akunt., vol. 1, no. 1, 2013.

[5] G. ARMANDO, "Pengaruh sistempengendalian intern pemerintah dan pengawasan keuangandaerah terhadap nilai informasi laporankeuangan pemerintah," J. Akunt., vol. 1, no. 1, pp. 1-25, 2013.

[6] P. I. Setyoko, "Akuntabilitas Administrasi Keuangan Program Alokasi Dana Desa ( ADD )," J. Ilmu Adm. Negara, vol. 11, no. 1, pp. 14-24, 2011.

[7] F. P. Kusuma, I. N. M. Yasa, and I. K. Djayastra, "KABUPATEN JEMBRANA Fakultas Ekonomi dan Bisnis Universitas Udayana, Bali, Indonesia ABSTRAK PENDAHULUAN Sebagai bentuk pertanggungjawaban dalam penyelenggaraan pemerintah yang diatur dalam Undang-Undang Nomor 17 tahun 2003 tentang Keuangan Negara dan Un,” E-Jurnal Ekon. dan Bisnis Univ. Udayana, vol. 5, no. 12, pp. 4115-4150, 2016.

[8] M. Prasetya and S. A. Irwandi, "FAKTOR - FAKTOR YANG MEMPENGARUHI PELAPORAN KEUANGAN MELALUI INTERNET ( INTERNET FINANCIAL REPORTING ) PADA PERUSAHAAN MANUFAKTUR DI BURSA EFEK INDONESIA," Indones. Account. Rev., vol. 2, no. 2, pp. 151-158, 2012.

[9] F. L. Sembiring, "PROGRAM STUDI AKUNTANSI FAKULTAS EKONOMI UNIVERSITAS NEGERI PADANG Wisuda Periode Maret 2013," J. Akunt., pp. 1-10, 2013.

[10] D. TRIYANTI, "PERLAKUAN AKUNTANSI TERHADAP BAGI HASIL BANK SYARIAH DITINJAU DARI SISTEM PENDANAAN, SISTEM PEMBIAYAAN, DAN LAPORAN KEUANGAN PADA BANK SYARIAH MANDIRI CABANG SURAKARTA,” Universitas Muhammadiyah Surakarta, 2008.

[11] I. Kusumaningrum, "PENGARUH KEJELASAN SASARAN ANGGARAN, PENGENDALIAN AKUNTANSI DAN SISTEM PELAPORAN TERHADAP AKUNTABILITAS KINERJA INSTANSI PEMERINTAH PROVINSI JAWA TENGAH," Universitas Diponegoro, 2010.

[12] N. N. Keumala and D. Muid, "ANALISIS FAKTOR-FAKTOR YANG MEMPENGARUHI PELAPORAN KEUANGAN PERUSAHAAN MELALUI WEBSITE PERUSAHAAN," DIPONEGORO J. Account., vol. 2, no. 3, pp. 1-10, 2013.

[13] F. Rosalin, "FAKTOR-FAKTOR YANG MEMPENGARUHI KEUANGAN BADAN LAYANAN UMUM ( Studi pada BLU di Kota Semarang )," Universitas Diponegoro, 2011.

[14] A. S. Nurillah and D. Muid, "PENGARUH KOMPETENSI SUMBER DAYA MANUSIA, PEMANFAATAN TEKNOLOGI INFORMASI , DAN SISTEM KEUANGAN PEMERINTAH DAERAH ( Studi Empiris Pada SKPD Kota Depok )," DIPONEGORO J. 
Account., vol. 3, no. 2, pp. 1-13, 2014.

[15] D. ARFIANTI, "ANALISIS FAKTOR-FAKTOR YANG MEMPENGARUHI NILAI INFORMASI PELAPORAN KEUANGAN PEMERINTAH DAERAH (Studi pada Satuan Kerja Perangkat Daerah di Kabupaten Batang)," Universitas Diponegoro, 2011.

[16] T. SUKMANINGRUM, "ANALISIS FAKTOR-FAKTOR YANG MEMPENGARUHI KUALITAS INFORMASI LAPORAN KEUANGAN PEMERINTAH DAERAH (Studi Empiris pada Pemerintah Kabupaten dan Kota Semarang)," Universitas Diponegoro, 2012.

[17] R. DWIYANTI, "ANALISIS FAKTOR-FAKTOR YANG MEMPENGARUHI KETEPATAN WAKTU PELAPORAN KEUANGAN PADA PERUSAHAAN MANUFAKTUR YANG TERDAFTAR DI BURSA EFEK INDONESIA," Univesitas Diponegoro, 2010.

[18] A. Kadir, "FAKTOR-FAKTOR YANG BERPENGARUH TERHADAP KETEPATAN WAKTU PELAPORAN KEUANGAN STUDI EMPIRIS PADA PERUSAHAAN MANUFAKTUR DI BURSA EFEK JAKARTA," J. Manaj. dan Akunt., vol. 12, no. 1, pp. 112, 2011.

[19] R. J. Howell, “The Guttman Approach to Modeling Drug Sequences :," vol. 6, no. 3, pp. 1-15, 2010.

[20] R. D. Hays and P. L. Ellickson, "Guttman scale analysis of longitudinal data: A methodology and drug use applications," Substance Use and Misuse, vol. 25, no. S11. pp. 1341-1352, 1990.

[21] V. K. Gothwal, T. A. Wright, E. L. Lamoureux, and K. Pesudovs, "Guttman scale analysis of the distance vision scale," Investig. Ophthalmol. Vis. Sci., vol. 50, no. 9, pp. 4496-4501, 2009.

[22] R. Meenan, P. German, J. Mason, and R. Dunaif, "The Arthritis Impact Measurement scales," Arthritis Rheum., vol. 25, no. 9, pp. 1048-1053, 1982.

[23] R. A. Deyo, A. K. Diehl, H. P. Hazuda, and M. P. Stern, "A simple language based acculturation scale for Mexican Americans: Validation and application to health care research,” Am. J. Public Health, vol. 75, no. 1, pp. 51-55, 1985. 